\title{
An exploratory study of three-dimensional MP-PIC-based simulation of bubbling fluidized beds with and without baffles
}

\author{
Yang, Shuai; Wu, Hao; Lin, Weigang; Li, Hongzhong; Zhu, Qingshan
}

Published in:
Particuology

Link to article, DOI:

10.1016/j.partic.2017.10.003

Publication date:

2018

Document Version

Peer reviewed version

Link back to DTU Orbit

Citation (APA):

Yang, S., Wu, H., Lin, W., Li, H., \& Zhu, Q. (2018). An exploratory study of three-dimensional MP-PIC-based simulation of bubbling fluidized beds with and without baffles. Particuology, 39, 68-77.

https://doi.org/10.1016/j.partic.2017.10.003

\section{General rights}

Copyright and moral rights for the publications made accessible in the public portal are retained by the authors and/or other copyright owners and it is a condition of accessing publications that users recognise and abide by the legal requirements associated with these rights.

- Users may download and print one copy of any publication from the public portal for the purpose of private study or research.

- You may not further distribute the material or use it for any profit-making activity or commercial gain

- You may freely distribute the URL identifying the publication in the public portal 


\section{An exploratory study of three-dimensional MP-PIC-based simulation of bubbling fluidized beds with and without baffles}

Shuai Yang ${ }^{\mathrm{a}, \mathrm{b}, \mathrm{c}, \mathrm{d}}$, Hao $\mathrm{Wu}^{\mathrm{c}, *}$, Weigang Lin ${ }^{\mathrm{a}, \mathrm{c}}$, Hongzhong Li ${ }^{\mathrm{a}, *}$, Qingshan $\mathrm{Zhu}^{\mathrm{a}}$

\section{Highlights:}

- Hydrodynamics of Geldart A particles in BFB with baffles were simulated using MP-PIC method.

- A modified structure-based (MSB) drag model and other two models were adopted in the simulation.

- MSB performed better than the other models tested in predicting the gas-solid flow.

- The MSB drag model need to be improved for adoption in CPFD to obtain accurate predictions. 


\title{
An exploratory study of three-dimensional MP-PIC-based simulation of bubbling fluidized beds with and without baffles
}

\author{
Shuai Yang a, b, c, d, Hao $\mathrm{Wu}^{\mathrm{c}, *}$, Weigang Lin ${ }^{\mathrm{a}, \mathrm{c}}$, Hongzhong Li ${ }^{\mathrm{a}, *}$, Qingshan $\mathrm{Zhu}^{\mathrm{a}}$

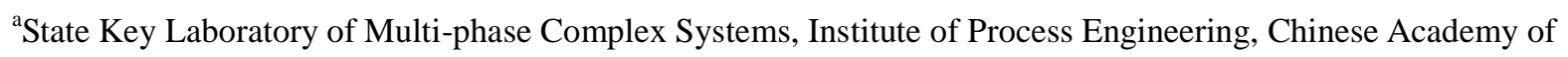 \\ Sciences, P.O. Box 353, Beijing 100190, China \\ ${ }^{\mathrm{b}}$ State Key Laboratory of Safety and Control for Chemicals, SINOPEC Research Institute of Safety Engineering, \\ Qingdao 266071, China \\ ${ }^{c}$ Department of Chemical and Biochemical Engineering, Technical University of Denmark, DK-2800, Kongens Lyngby, \\ Denmark \\ ${ }^{\mathrm{d}}$ Sino-Danish College, University of Chinese Academy of Sciences, Beijing 100049, China \\ *Corresponding authors. E-mail: haw@kt.dtu.dk (H.Wu); hzli@ipe.ac.cn (H. Li)
}

\begin{abstract}
In this study, the flow characteristics of Geldart A particles in a bubbling fluidized bed with and without perforated plates were simulated by the multiphase particle-in-cell (MP-PIC)-based Eulerian-Lagrangian method. A modified structure-based drag model was developed based on our previous work. Other drag models including the Parker and Wen-Yu-Ergun drag models were also employed to investigate the effects of drag models on the simulation results. Although the modified structure-based drag model better predicts the gas-solid flow dynamics of a baffle-free bubbling fluidized bed in comparison with the experimental data, none of these drag models predict the gas-solid flow in a baffled bubbling fluidized bed sufficiently well because of the treatment of baffles in the Barracuda software. To improve the simulation accuracy, future versions of Barracuda should address the challenges of incorporating the bed height and the baffles.
\end{abstract}

Keywords: Baffle; Geldart A particles; Bubbling fluidized beds; Simulation; Multi-phase particle-in-cell; Computational particle fluid dynamics

\section{Introduction}

Gas-solid bubbling fluidized beds (BFBs) are widely used in industrial processes such as fluid catalytic cracking (FCC) regeneration and coal gasification (Daizo \& Levenspiel, 1991). However, the presence of bubbles in BFBs results in poor contact between gas and solid, back-mixing of particles, and entrainment of fine particles. Different methods may be applied to overcome these problems, such as adding internal baffles, using an external force field, or changing the particle and fluid properties (Li \& Kwauk, 2002). Among these approaches, adding internal baffles is a relatively simple and low-cost method (Harrison \& Grace, 1971; Jin, Yu, Zhang, Shen, \& Wang, 1982). Perforated plates are the most commonly used type of baffle in industrial applications because of 
their ability to improve the uneven radial distribution of particles in fluidized beds (Kwauk \& $\mathrm{Li}, 2007$ ). Therefore, it is important to understand how the configuration of the perforated plates affects the hydrodynamics of BFBs.

With the rapid development of computational capability, computational fluid dynamics (CFD) has become an efficient way to explore the hydrodynamics in different types of reactor (Wang \& Liu, 2010; Gidaspow, Jung, \& Singh, 2004; Mckeen \& Pugsley, 2003; Zhong, Gao, Xu, \& Lan, 2012). Generally speaking, the methods for modeling the gas-solid system can be categorized into Eulerian-Eulerian (EE), Eulerian-Lagrangian (EL), and Lagrangian-Lagrangian approaches. Of these, the first two methods are widely used to simulate fluidized beds. For the EE approach, both the solid and fluid phases are considered as continua. Because of the continuum hypothesis for the solid phase, the EE method needs additional closure models to describe the interparticle and particle-wall interactions. Although continuous efforts have been made to develop closure models, it remains challenging for the EE method to simulate flows with distributed particle size and type because the continuity and momentum equations must be solved separately for each size and type of particle (Gidaspow, 1994; Rizk, 1993). This shortcoming may be overcome by using the EL method, which accounts the collisions of particles and the external forces acting on them without additional closure equations for the solid phase (Goldschmidt, Hoomans, \& Kuipers, 2002). However, tracking all particles is computationally expensive. Thus, the EL method needs greater computing capability than does the EE method. Currently, the EL method can handle up to $10^{9}$ particles (Lu et al., 2014, 2016), but that is still far from the number of particles in industrial-scale reactors.

To address these challenges, Andrews and O'rourke (1996) proposed the multiphase particle-in-cell (MP-PIC) method (Snider, 2001) in which the solid is divided into several parcels of particles, each of which is referred to as a computational particle. All the particles in one parcel have the same properties (e.g., volume fraction, density, and velocity). The particle stress gradient, which is difficult to compute for each particle, is solved on a grid and then interpolated to the particles (Andrews \& O'rourke, 1996; Snider, 2001; Pannala, Syamlal, \& O'Brien, 2011; Snider, Clark, \& O'Rourke, 2011). This method of computing the particle stress gradient and treating the particles solves the problem of computational complexity and cost associated with the EL method. With an isotropic particle stress gradient added to the equation of motion of the particles, flows with any particle volume fraction from dilute to close-packed can be calculated (Andrews \& O'rourke, 1996; Snider, 2001; Pannala et al., 2011). Thus, the MP-PIC-based EL method can simulate systems with high solid concentration in relatively short computational time. To date, the MP-PIC-based EL method has been applied to reactors in the fast, turbulent, and bubbling fluidization regime with coarse and fine particles (Wang et al., 2014; Abbasi, Ege, \& De Lasa, 2011; Chen, Werther, Heinrich, Qi, \& Hartge, 2013; Shi et al., 2015; Vivacqua, Vashisth, Hebrard, Grace, \& Epstein, 2012; Li, Song, Benyahia, Wang, \& Li, 2012; Liang, Zhang, Li, \& Lu, 2014; Benyahia \& Sundaresan, 2012; Karimipour \& Pugsley, 2012). However, to the best of our knowledge, this approach has yet to be applied to baffled BFBs with fine particles. Hence, the applicability of the MP-PIC-based EL method to BFBs with and without baffles needs to be explored. 
In this work, we use the MP-PIC-based EL method to simulate a BFB with perforated plates. A modified structure-based (MSB) drag model is developed for the simulations. Hydrodynamic aspects such as the radial and axial distributions of solid concentration in the BFB are predicted and compared with existing experimental data and simulation results obtained using the EE method (Yang, Li, \& Zhu, 2015).

\section{Simulations}

The simulations were conducted using the computational particle fluid dynamics (CPFD) software Barracuda VR 17.0. This solves the fluid dynamics in three dimensions using the averaged Navier-Stokes equations and the particle momentum equation with the MP-PIC formulation (Andrews \& O'rourke, 1996; Snider, 2001). The governing equations are summarized in Table 1.

Table 1

\subsection{Simulation systems}

The simulations are based on a gas-solid bubbling fluidized system used in our previous work (Yang et al., 2015). As illustrated in Fig. 1, the simulated part is a column that is $140 \mathrm{~mm}$ in diameter and $1,000 \mathrm{~mm}$ tall. The particles are glass beads with a size distribution as shown in Fig. 2. The other relevant particle properties are given in Table 2. The baffles used in the experiment were perforated plates as shown in Fig. 3, each of which contains 12 holes of $20 \mathrm{~mm}$ in diameter; the area fraction of the openings is $25.2 \%$. In the two-compartment baffled BFB, the perforated plates were mounted at heights of 0.135 and $0.235 \mathrm{~m}$ above the distributor. The operating conditions in the experiment and parameter settings in the simulation are given in Table 3.

Figs. 1, 2, \& 3, Tables $2 \& 3$

\subsection{Drag models}

In CFD simulations of gas-solid BFBs, drag models are vitally important for predicting the hydrodynamics. To investigate the influence of drag models on the CPFD simulation results, we use three drag models in the present simulations, namely a structure-based drag model (Lv, Li, \& Zhu, 2014), the Wen-Yu-Ergun (WYE) (Gidaspow) drag model (Gidaspow, 1994), and the Parker drag model (Parker, 2015). In Barracuda, the drag force is based on a single particle (Parker, 2015). The expression for the drag force based on a single particle can be written as

$$
F_{\mathrm{p}}=m_{\mathrm{p}} D\left(\mathbf{u}_{\mathrm{g}}-\mathbf{u}_{\mathrm{p}}\right)
$$

where 


$$
D=\frac{3}{8} C_{\mathrm{d}} \frac{\rho_{\mathrm{g}}\left|\mathbf{u}_{\mathrm{g}}-\mathbf{u}_{\mathrm{p}}\right|}{\rho_{\mathrm{p}} r_{\mathrm{p}}},
$$

and

$$
R e=\frac{2 \rho_{\mathrm{g}} r_{\mathrm{p}}\left|\mathbf{u}_{\mathrm{g}}-\mathbf{u}_{\mathrm{p}}\right|}{\mu_{\mathrm{g}}} .
$$

\subsubsection{Modified structure-based drag model}

We have previously validated the structure-based drag model, which is a function of the bed height (Lv et al., 2014). However, drag models that contain the bed height cannot be implemented directly in the present version of Barracuda. Thus, this drag model is applied with modifications.

In the structure-based drag model (Lv et al., 2014), the empirical equation of bubble diameter includes the bed height as a variable. To implement this drag model in Barracuda, we replaced the equation for predicting the bubble diameter by the following equation proposed by Horio and Nonaka (1987):

$$
d_{\mathrm{b}}=\left[-\gamma_{\mathrm{M}}+\left(\gamma_{\mathrm{M}}^{2}+4 d_{\mathrm{bm}} / D_{\mathrm{t}}\right)^{0.5}\right]^{2} D_{\mathrm{t}} / 4
$$

The parameter $\gamma_{M}$ can be calculated by

$$
\gamma_{\mathrm{M}}=2.56 \times 10^{-2}\left(D_{\mathrm{t}} / g\right)^{0.5} / U_{\mathrm{gc}}
$$

and $d_{\mathrm{bm}}$ is the maximum bubble diameter from total coalescence of the bubbles, which can be calculated by

$$
d_{\mathrm{bm}}=2.59 g^{-0.2}\left[\left(U_{\mathrm{g}}-U_{\mathrm{gc}}\right) \pi D_{\mathrm{t}}^{2} / 4\right]^{0.4}
$$

The other equations are kept the same as in the original model ( $\mathrm{Lv}$ et al., 2014). Thus, the heterogeneous index defined as a dimensionless drag coefficient scaled with the Wen-Yu model needs to be recalculated based on Lv's method (Lv et al., 2014) as follows:

$$
H_{\mathrm{d}}=\beta_{\text {Structure-based }} / \beta_{\text {Wen \&Yu }}=\frac{\overline{C_{\mathrm{D}}}}{C_{\mathrm{D}} \theta_{\mathrm{f}}^{-4.7}},
$$




$$
\beta=\frac{F_{\mathrm{D}} \theta_{\mathrm{f}}}{\left(u_{\mathrm{g}}-u_{\mathrm{p}}\right)} .
$$

Table 4 gives the heterogeneous index of the MSB drag model for superficial gas velocities of 0.054 and $0.072 \mathrm{~m} / \mathrm{s}$. Based on Lv's work (Lv et al., 2014), the drag model used herein is as follows:

$$
\beta=\left\{\begin{array}{c}
150 \frac{\theta_{\mathrm{p}}\left(1-\theta_{\mathrm{f}}\right) \mu_{\mathrm{g}}}{\theta_{\mathrm{f}} d_{\mathrm{p}}^{2}}+1.75 \theta_{\mathrm{p}} \frac{\rho_{\mathrm{g}}}{d_{\mathrm{p}}}\left|u_{\mathrm{g}}-u_{\mathrm{s}}\right|, \quad\left(0 \sim \theta_{\mathrm{mf}}\right) \\
0.75 C_{\mathrm{D}} \frac{\theta_{\mathrm{f}} \theta_{\mathrm{p}} \rho_{\mathrm{g}}\left|u_{\mathrm{g}}-u_{\mathrm{s}}\right|}{d_{\mathrm{p}}} \theta_{\mathrm{f}}^{-2.65} H_{\mathrm{d}}, \quad\left(\theta_{\mathrm{mf}} \sim \theta_{\mathrm{d}}\right) \\
0.75 C_{\mathrm{D}} \frac{\theta_{\mathrm{f}} \theta_{\mathrm{p}} \rho_{\mathrm{g}}\left|u_{\mathrm{g}}-u_{\mathrm{s}}\right|}{d_{\mathrm{p}}} \theta_{\mathrm{f}}^{-2.65}, \quad\left(\theta_{\mathrm{d}} \sim 1\right)
\end{array}\right.
$$

Table 4

\subsubsection{Wen-Yu-Ergun drag model}

The WYE drag model is a hybrid drag model involving the Wen-Yu drag model adapted for dilute gas-solid flow and the Ergun drag model fitted for dense gas-solid flow (Gidaspow, 1994). This traditional drag model is based on the following homogeneous gas-solid flow assumption:

$$
D=\left\{\begin{array}{cc}
D_{1} & \theta_{\mathrm{p}}<0.75 \theta_{\mathrm{CP}} \\
\left(D_{2}-D_{1}\right)\left(\frac{\theta_{\mathrm{p}}-0.75 \theta_{\mathrm{CP}}}{0.85 \theta_{\mathrm{CP}}-0.75 \theta_{\mathrm{CP}}}\right)+D_{1} & 0.75 \theta_{\mathrm{CP}} \geq \theta_{\mathrm{p}} \geq 0.85 \theta_{\mathrm{CP}} . \\
D_{2} & \theta_{\mathrm{p}}>0.85 \theta_{\mathrm{CP}}
\end{array}\right.
$$

The parameter $D_{1}$ represents the drag function of the Wen-Yu drag model and $D_{2}$ represents the drag function of the Ergun drag model, which are expressed respectively as

$$
\begin{aligned}
& D_{1}=\frac{3}{8} C_{\mathrm{d}} \frac{\rho_{\mathrm{g}}\left|\mathbf{u}_{\mathrm{g}}-\mathbf{u}_{\mathrm{p}}\right|}{\rho_{\mathrm{p}} r_{\mathrm{p}}}, \\
& D_{2}=0.5\left(\frac{C_{1} \theta_{\mathrm{p}}}{\theta_{\mathrm{g}} \operatorname{Re}}+C_{2}\right) \frac{\rho_{\mathrm{g}}\left|\mathbf{u}_{\mathrm{f}}-\mathbf{u}_{\mathrm{p}}\right|}{r_{\mathrm{p}} \rho_{\mathrm{p}}} .
\end{aligned}
$$

The drag coefficient $C_{\mathrm{d}}$ is a function of Reynolds number: 


$$
C_{\mathrm{d}}=\left\{\begin{array}{cc}
\frac{24}{\operatorname{Re}} \theta_{\mathrm{g}}^{-2.65} & R e<0.5 \\
\frac{24}{\operatorname{Re} \theta_{\mathrm{g}}^{-2.65}\left(1+0.15 R e^{0.687}\right)} & 0.5 \leq R e \leq 1000 . \\
0.44 \theta_{\mathrm{g}}^{-2.65} & R e>1000
\end{array}\right.
$$

\subsubsection{Parker drag model}

The Parker drag model (Parker, 2015), which adds an empirical agglomeration model, is a continuous drag model correlating the two extremes of the close-packed and single-particle states. The model is expressed as

$$
\begin{aligned}
& F_{\mathrm{p}}(\varepsilon, R e)=F_{\mathrm{SP}}(R e)^{\chi} F_{\mathrm{mf}}{ }^{1-\chi}, \\
& \chi=1-\frac{\ln \varepsilon}{\ln \varepsilon_{\mathrm{mf}}}, \\
& F_{\mathrm{SP}}(R e)=\left\{\begin{array}{cc}
1+0.15 R e^{0.687} & R e<1000 \\
\frac{0.44}{24} R e & R e \geq 1000
\end{array},\right. \\
& F_{\mathrm{mf}}=\frac{a}{18} \frac{1-\varepsilon_{\mathrm{mf}}}{\phi^{2} \varepsilon_{\mathrm{mf}}^{2}}+\frac{b}{18} \frac{R e}{\phi \varepsilon_{\mathrm{mf}}^{2}} .
\end{aligned}
$$

\subsection{Grid-independence test}

In Barracuda, the grids inside the geometry are veridical hexahedron meshes and those near the boundary comprise body-fitted arbitrary polyhedrons (Ingram, Causon, \& Mingham, 2003). To ensure that the simulation results are independent of grid size, we tested two grid sizes $(2.5 \mathrm{~mm} \times 2.5 \mathrm{~mm} \times 2.5 \mathrm{~mm}$ and $5 \mathrm{~mm} \times 5 \mathrm{~mm} \times 5$ $\mathrm{mm}$ ) in calculation of the radial solid-concentration distribution at a superficial gas velocity of $0.072 \mathrm{~m} / \mathrm{s}$. As shown in Fig. 4, there is no obvious difference between the simulation results for the two grid sizes. Considering the accuracy and the calculation time, we selected the $5 \mathrm{~mm} \times 5 \mathrm{~mm} \times 5 \mathrm{~mm}$ grid for the rest of the simulations.

Fig. 4

\subsection{Effect of particle number per parcel}

In the CPFD model, the number of particles in a parcel influences the simulation results significantly. Having more particles in a parcel reduces the computation time but may lead to underestimating the particle flux (Liang, 
Zhang, $\mathrm{Li}, \& \mathrm{Lu}, 2014)$. Therefore, it is vital to have a reasonable number of particles per parcel; based on the operating conditions in the experiments (Yang et al., 2015), we chose $3.76 \times 10^{10}$ particles. To investigate how the number of particles per parcel affects the simulation results, we tried 50, 100, and 200 particles per parcel and $7.52 \times 10^{8}, 3.76 \times 10^{8}$, and $1.88 \times 10^{8}$ parcels, respectively. The radial distributions of solid volume fraction calculated with the MSB drag model with different parcel numbers under a superficial gas velocity of $0.072 \mathrm{~m} / \mathrm{s}$ are shown in Fig. 5. The results indicate little influence of the number of particles per parcel on the results. Thus, considering the accuracy and the computation time, we chose 200 particles per parcel for the simulations.

Fig. 5

\section{Results and discussion}

\subsection{Baffle-free bubbling fluidized bed}

Fig. 6 shows the profiles of particle volume fraction calculated with the three drag models at a superficial gas velocity of $0.072 \mathrm{~m} / \mathrm{s}$ in the baffle-free BFB. For each drag model, the simulation results show that the bed fluidizes, but different phenomena are observed at the bottom of the BFB. Slugging is observed with the Parker and WYE drag models (see Fig. 6(b) and (c), respectively), which is not realistic in a BFB with Geldart A particles and is not consistent with experimental observations. The results in Fig. 6(a) show that the MSB drag model, which does not predict slugging, agrees qualitatively with the experimental observations.

Fig. 6

To compare the different drag models quantitatively, we compare in Fig. 7 the calculated radial distributions of solid volume fraction with the experimental data (Yang et al., 2015) in the baffle-free BFB under superficial gas velocities of 0.054 and $0.072 \mathrm{~m} / \mathrm{s}$. The simulation results with the Parker drag model give gentle radial distributions of solid volume fraction, but those predicted with the WYE and MSB drag models seem more fluctuant. However, none of the drag models predict the solid concentration distributions accurately in the top part of the BFB; the discrepancy between the simulation results and the experimental data increases with bed height, and the simulation results overestimate the solid volume fraction in comparison with the experimental data. In addition, the simulated radial distributions of solid volume fraction remain the same as the bed height increases, indicating that the drag force is nearly independent of bed height. In the MSB drag model, the empirical equation for bubble diameter represents the maximum stable bubble diameter, which is independent of bed height in the BFB. Hence, the drag force is unrelated to bed height. For the drag force determines the solid distribution, the solid volume fraction is still independent with bed height, almost the same with the bed height increasing in the dense region.

Fig. 7 
Considering the simulation results shown in Figs. 6 and 7, it seems that the MSB drag model provides more accurate simulation at the bottom of the BFB. However, none of the drag models give reasonable prediction of the hydrodynamics in the whole baffle-free BFB. In the MP-PIC-based EL method, a certain number of particles are treated as a parcel. This treatment may homogenize the particle motion and influence the simulation accuracy.

In future work, the MSB drag model should be improved. In addition, the bed height may become the most important factor, and future versions of Barracuda should address the challenges of incorporating the bed height.

\subsection{Baffled bubbling fluidized bed}

Fig. 8 shows a comparison of the radial distributions of solid volume fraction calculated with these three drag models together with the experimental data at superficial gas velocities of 0.054 and $0.072 \mathrm{~m} / \mathrm{s}$ in the BFB with two layers of perforated plates. Similar to the simulations of the baffle-free BFB, the simulated results agree better with the experimental data in the lower part of the bed. Fig. 9 shows a comparison of the profiles of particle volume fraction under a superficial gas velocity of $0.072 \mathrm{~m} / \mathrm{s}$ in the BFB with two layers of perforated plates. Similar to the results shown in Fig. 6, the Parker and WYE drag models predict unreasonable slugging at the bottom of the bed. Although the gas-solid flow calculated with the MSB drag model is visually consistent with the experimental phenomena, neither can that model predict the hydrodynamics precisely at higher bed height. In addition, similar radial distributions of solid volume fraction may exist in different flow regimes. Hence, it is necessary to combine the profile of particle volume fraction and the radial distribution of solid volume fraction to demonstrate the validity of a drag model.

Figs. $8 \& 9$

In the experimental study with two layers of perforated plates, a dilute region (also called a gas cushion) was observed under each layer of perforated plates (Yang et al., 2015). However, in Fig. 9, no such gas cushion is observed. Furthermore, in Fig. 10 we compare the axial distributions of solid volume fraction in the BFBs with and without perforated plates as simulated with the MSB drag model using the CPFD software Barracuda 17.0 and CFD software Fluent 6.3.26. The axial distributions of solid volume fraction calculated using Fluent 6.3.26 agree with the experimental data (Yang et al., 2015). The results obtained using Barracuda do not show the effect of the perforated plates on the hydrodynamics in the BFB. In the current version of Barracuda, baffles have no influence on the movement of particles, only hindering the gas from passing through the cross section of the reactor. This phenomenon is due to how the baffles are treated, resulting in poorer accuracy of simulations of baffled BFBs.

Fig. 10 
To get better predictions of baffled BFBs, the way in which Barracuda treats baffles should be improved. In the current version, particles can pass through baffles without impediment, which is not consistent with experimental results. Furthermore, the effect of the baffle structure on the flow dynamics is not reflected.

\title{
4. Conclusions
}

The hydrodynamics of Geldart A particles in gas-solid BFBs with and without perforated plates were simulated using the MP-PIC-based EL method. The MSB, Parker, and WYE drag models were applied to CPFD to explore the possibility of simulating the BFBs. Of these drag models, the MSB drag model performed the best. However, the results of predicting the gas-solid flow were not good enough compared with the experimental data. In addition, for comparison with experimental data, it is not sufficient to compare only the profiles of solid volume fraction; the detailed structure of the fluid dynamics should be examined carefully as well. To increase the simulation accuracy, the MSB drag model should be improved. In addition, the way in which Barracuda treats baffles should be promoted as well.

\section{Acknowledgments}

This work was supported by (i) the Sino-Danish Center for Education and Research, (ii) the Sino-Danish collaboration project (DANCNGAS) funded by the Innovation Fund Denmark, (iii) the MiCeTech project funded by the Danish National Advanced Technology Foundation, FLSmidth A/S, and the Technical University of Denmark, (iv) the State Key Development Program for Basic Research of China (973 Program), grant number 2015CB251402, and (v) the National Natural Science Foundation of China, grant number 21325628.

\section{Nomenclature}

\author{
$C_{\mathrm{D}} \quad$ drag coefficient \\ $D \quad$ fluidized bed diameter (m) \\ $D_{1} \quad$ drag function of Wen-Yu drag model $\left(\mathrm{s}^{-1}\right)$ \\ $D_{2} \quad$ drag function of Ergun drag model $\left(\mathrm{s}^{-1}\right)$ \\ $d_{\mathrm{b}} \quad$ bubble diameter $(\mathrm{m})$ \\ $d_{\mathrm{bm}} \quad$ maximum bubble diameter $(\mathrm{m})$ \\ $d_{\text {bo }} \quad$ initial bubble size (m)
}




$\begin{array}{ll}d_{\mathrm{p}} & \text { diameter of particles }(\mathrm{m}) \\ e & \text { restitution coefficient } \\ g & \text { gravitational acceleration }\left(\mathrm{m} / \mathrm{s}^{2}\right) \\ g_{0} & \text { radial distribution function } \\ h & \text { height of the reactor (m) } \\ H_{\mathrm{d}} & \text { heterogeneous index } \\ P & \text { pressure (pa) } \\ U_{\mathrm{g}} & \text { superficial gas velocity (m/s) } \\ U_{\mathrm{mf}} & \text { superficial minimum fluidization velocity }(\mathrm{m} / \mathrm{s})\end{array}$

Greek symbols

$\beta \quad$ drag coefficient $\left(\mathrm{kg} /\left(\mathrm{m}^{3} \mathrm{~s}\right)\right)$

$\theta_{\mathrm{d}} \quad$ maximum voidage in fitting $H_{\mathrm{d}}$ function

$\theta_{\mathrm{f}} \quad$ average voidage

$\theta_{\mathrm{mf}} \quad$ voidage at minimum fluidization

$\theta_{\mathrm{p}} \quad$ solid volume fraction

$\theta_{\mathrm{CP}} \quad$ volume fraction of particles in close-packed particle bed

$\rho \quad$ density $\left(\mathrm{kg} / \mathrm{m}^{3}\right)$

$\mu \quad$ viscosity (Pa s)

$\tau \quad$ stress tensor (Pa)

$\Theta \quad$ granular temperature $\left(\mathrm{m}^{-2} \mathrm{~s}^{-2}\right)$

Subscripts 


$\begin{array}{ll}\mathrm{b} & \text { bubble } \\ \mathrm{f} & \text { fluid phase } \\ \mathrm{mf} & \text { minimum fluidization } \\ \mathrm{p} & \text { particle }\end{array}$

\section{References}

Abbasi, A., Ege, P. E., \& De Lasa, H. I. (2011). CPFD simulation of a fast fluidized bed steam coal gasifier feeding section. Chemical Engineering Journal, 174(1), 341-350.

Andrews, M. J., \& O'rourke, P. J. (1996). The multiphase particle-in-cell (MP-PIC) method for dense particulate flows. International Journal of Multiphase Flow, 22(2), 379-402.

Benyahia, S., \& Sundaresan, S. (2012). Do we need sub-grid scale corrections for both continuum and discrete gas-particle flow models?. Powder Technology, 220, 2-6.

Chen, C., Werther, J., Heinrich, S., Qi, H. Y., \& Hartge, E. U. (2013). CPFD simulation of circulating fluidized bed risers. Powder Technology, 235, 238-247.

Daizo, K., \& Levenspiel, O. (1991). Fluidization engineering. New York: Wiley.

Gidaspow, D. (1994). Multiphase flow and fluidization: Continuum and kinetic theory descriptions. New York: Academic Press.

Gidaspow, D., Jung, J., \& Singh, R. K. (2004). Hydrodynamics of fluidization using kinetic theory: An emerging paradigm: 2002 Flour-Daniel lecture. Powder Technology, 148(2), 123-141.

Goldschmidt, M. J. V., Hoomans, B. P. B., \& Kuipers, J. A. M. (2002). Detailed comparison of Euler-Lagrange and Euler-Euler models for simulation of dense gas fluidised beds. In Proceedings of the 10th Workshop on Two-phase Flow Predictions (pp. 285-299).

Harrison, D., \& Grace, J.R. (1971). Fluidized beds with internal baffles. In: J.F. Davidson \& D. Harrison (Eds.). Fluidization (Chapter 13). London: Academic Press.

Hong, K., Shi, Z., Wang, W., \& Li, J. (2013). A structure-dependent multi-fluid model (SFM) for heterogeneous gas-solid flow. Chemical Engineering Science, 99, 191-202. 
Horio, M., \& Nonaka, A. (1987). A generalized bubble diameter correlation for gas-solid fluidized beds. AIChE Journal, 33(11), 1865-1872.

Ingram, D. M., Causon, D. M., \& Mingham, C. G. (2003). Developments in Cartesian cut cell methods. Mathematics and Computers in Simulation, 61(3), 561-572.

Jin, Y., Yu, Z., Zhang, L., Shen, J., \& Wang, Z. (1982). Pagoda-shaped internal baffles for fluidized bed reactors. International Chemical Engineering, 22, 269-279.

Karimipour, S., \& Pugsley, T. (2012). Application of the particle in cell approach for the simulation of bubbling fluidized beds of Geldart A particles. Powder Technology, 220, 63-69.

Kwauk, M., \& Li, H. (2007). Handbook of fluidization (pp. 610-635). Beijing: Chemical Industry Press. (in Chinese)

Li, F., Song, F., Benyahia, S., Wang, W., \& Li, J. (2012). MP-PIC simulation of CFB riser with EMMS-based drag model. Chemical Engineering Science, 82, 104-113.

Li, H., \& Kwauk, M. (2002). Particulatization of gas-solids fluidization (pp. 38-104). Beijing: Chemical Industry Press. (in Chinese)

Liang, Y., Zhang, Y., Li, T., \& Lu, C. (2014). A critical validation study on CPFD model in simulating gas-solid bubbling fluidized beds. Powder Technology, 263, 121-134.

Liang, Y., Zhang, Y., Li, T., \& Lu, C. (2014). A critical validation study on CPFD model in simulating gas-solid bubbling fluidized beds. Powder Technology, 263, 121-134.

Lu, L., Xu, J., Ge, W., Gao, G., Jiang, Y., \& Zhao, M., et al. (2016). Computer virtual experiment on fluidized beds using a coarse-grained discrete particle method-EMMS-DPM. Chemical Engineering Science, 155, 314337.

Lu, L., Xu, J., Ge, W., Yue, Y., Liu, X., \& Li, J. (2014). EMMS-based discrete particle method (EMMS-DPM) for simulation of gas-solid flows. Chemical Engineering Science, 120, 67-87.

Lv, X., Li, H., \& Zhu, Q. (2014). Simulation of gas-solid flow in 2D/3D bubbling fluidized beds by combining the two-fluid model with structure-based drag model. Chemical Engineering Journal, 236, 149-157.

Mckeen, T., \& Pugsley, T. (2003). Simulation and experimental validation of a freely bubbling bed of FCC catalyst. Powder Technology, 129(1), 139-152. 
Mori, S., \& Wen, C. Y. (1975). Estimation of bubble diameter in gaseous fluidized beds. AIChE Journal, 21(1), $109-115$.

Pannala, S., Syamlal, M., \& O'Brien, T. J. (2011). Computational gas-solids flows and reacting systems: Theory, methods and practice. Hershey, PA: IGI Global.

Parker, J. M. (2015). Improving drag correlations for modeling of real particle fluidization. In Proceedings of the Inaugural Barracuda Virtual Reactor User' Conference, Santa Ana Pueblo, New Mexico.

Rizk, M. A. (1993). Mathematical modeling of densely loaded, particle-laden turbulent flows. Atomization and Sprays, 3(1), 1-27.

Shi, X., Sun, R., Lan, X., Liu, F., Zhang, Y., \& Gao, J. (2015). CPFD simulation of solids residence time and backmixing in CFB risers. Powder Technology, 271, 16-25.

Snider, D. M. (2001). An incompressible three-dimensional multiphase particle-in-cell model for dense particle flows. Journal of Computational Physics, 170(2), 523-549.

Snider, D. M., Clark, S. M., \& O'Rourke, P. J. (2011). Eulerian-Lagrangian method for three-dimensional thermal reacting flow with application to coal gasifiers. Chemical Engineering Science, 66(6), 1285-1295.

Vivacqua, V., Vashisth, S., Hebrard, G., Grace, J. R., \& Epstein, N. (2012). Characterization of fluidized bed layer inversion in a 191-mm-diameter column using both experimental and CPFD approaches. Chemical Engineering Science, 80, 419-428.

Wang, J., \& Liu, Y. (2010). EMMS-based Eulerian simulation on the hydrodynamics of a bubbling fluidized bed with FCC particles. Powder Technology, 197(3), 241-246.

Wang, Q., Yang, H., Wang, P., Lu, J., Liu, Q., \& Zhang, H., et al. (2014). Application of CPFD method in the simulation of a circulating fluidized bed with a loop seal, part I-Determination of modeling parameters. Powder Technology, 253, 814-821.

Yang, S., Li, H., \& Zhu, Q. (2015). Experimental study and numerical simulation of baffled bubbling fluidized beds with Geldart A particles in three dimensions. Chemical Engineering Journal, 259, 338-347.

Zhong, H., Gao, J., Xu, C., \& Lan, X. (2012). CFD modeling the hydrodynamics of binary particle mixtures in bubbling fluidized beds: Effect of wall boundary condition. Powder Technology, 230, 232-240. 


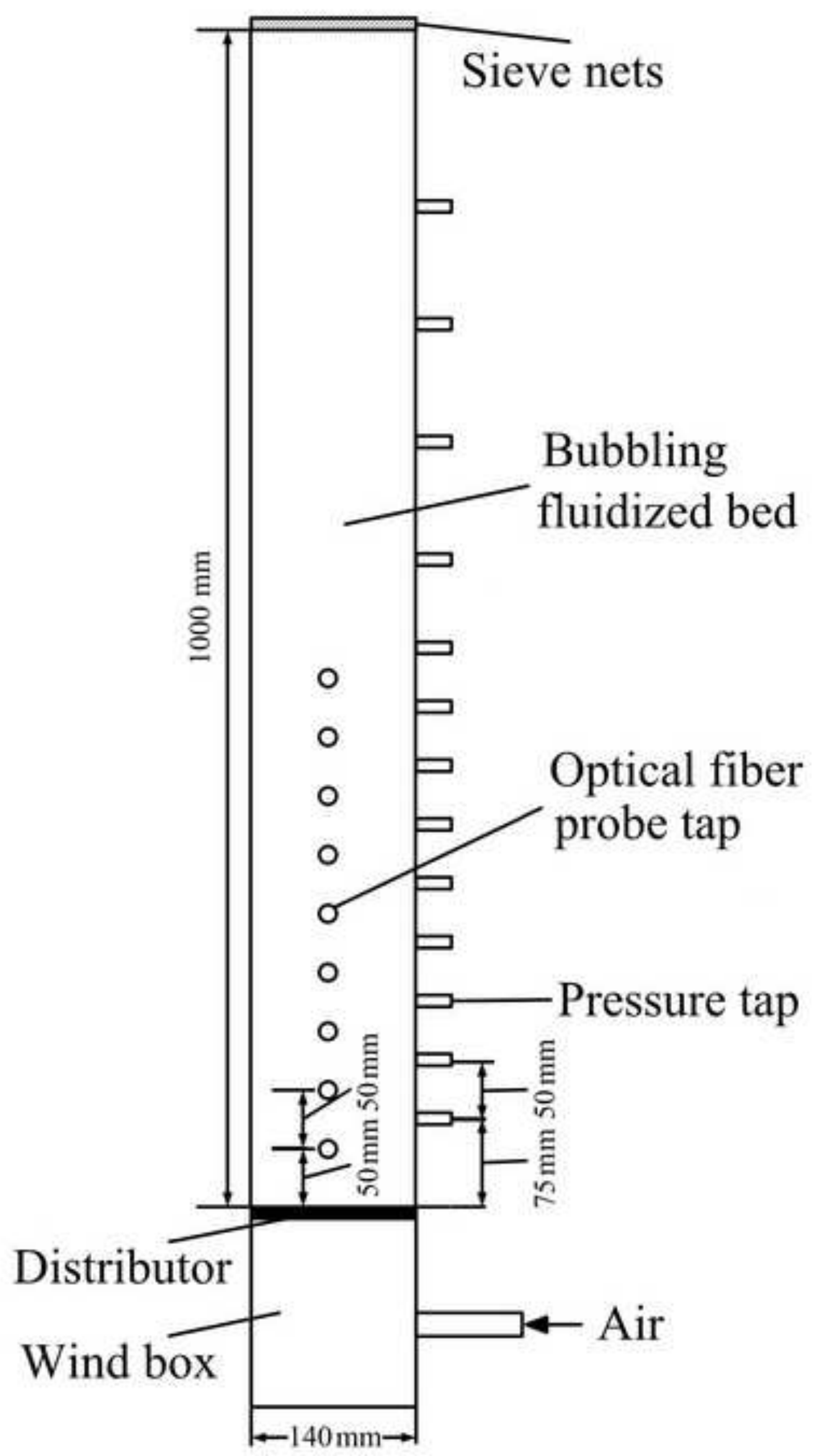




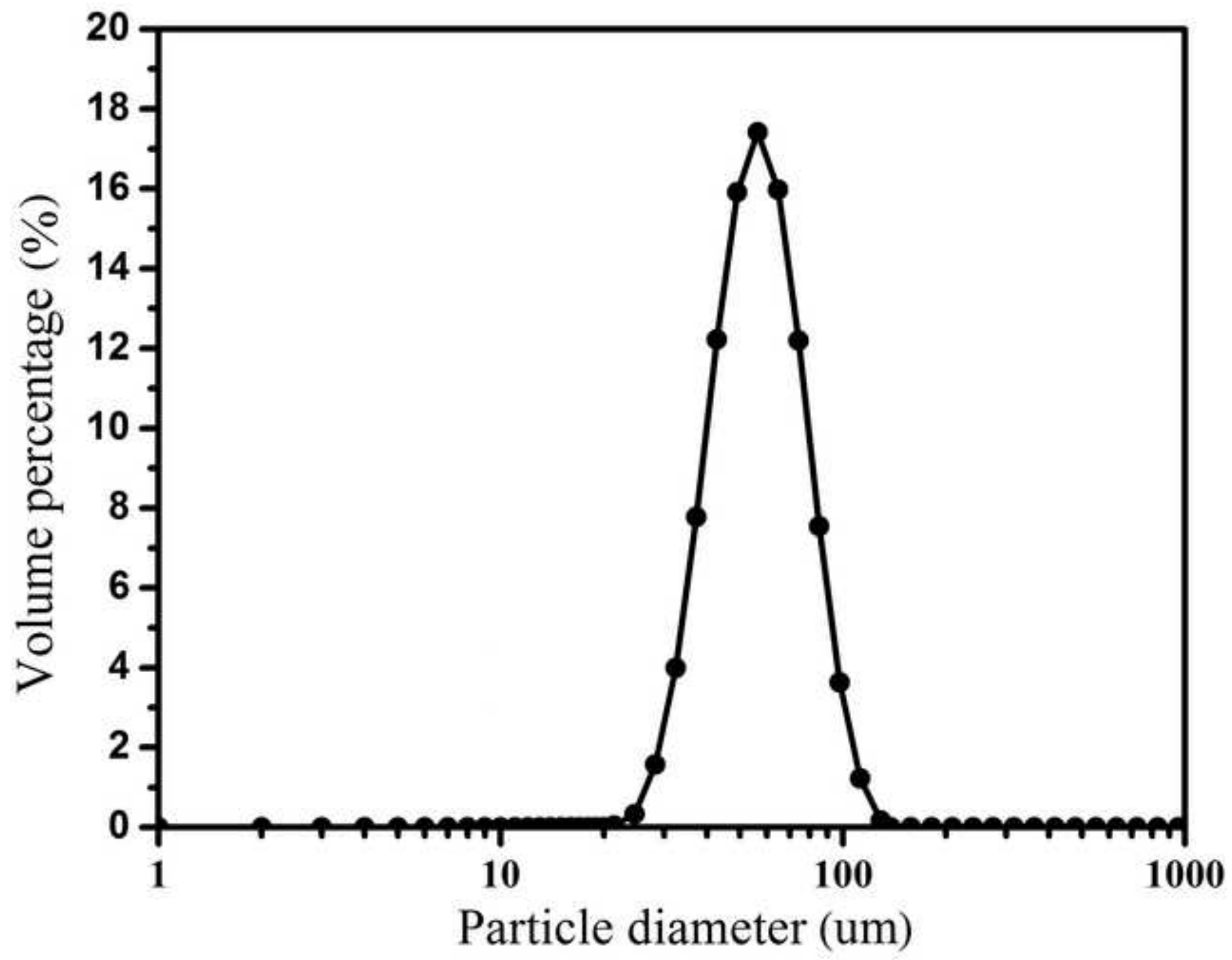




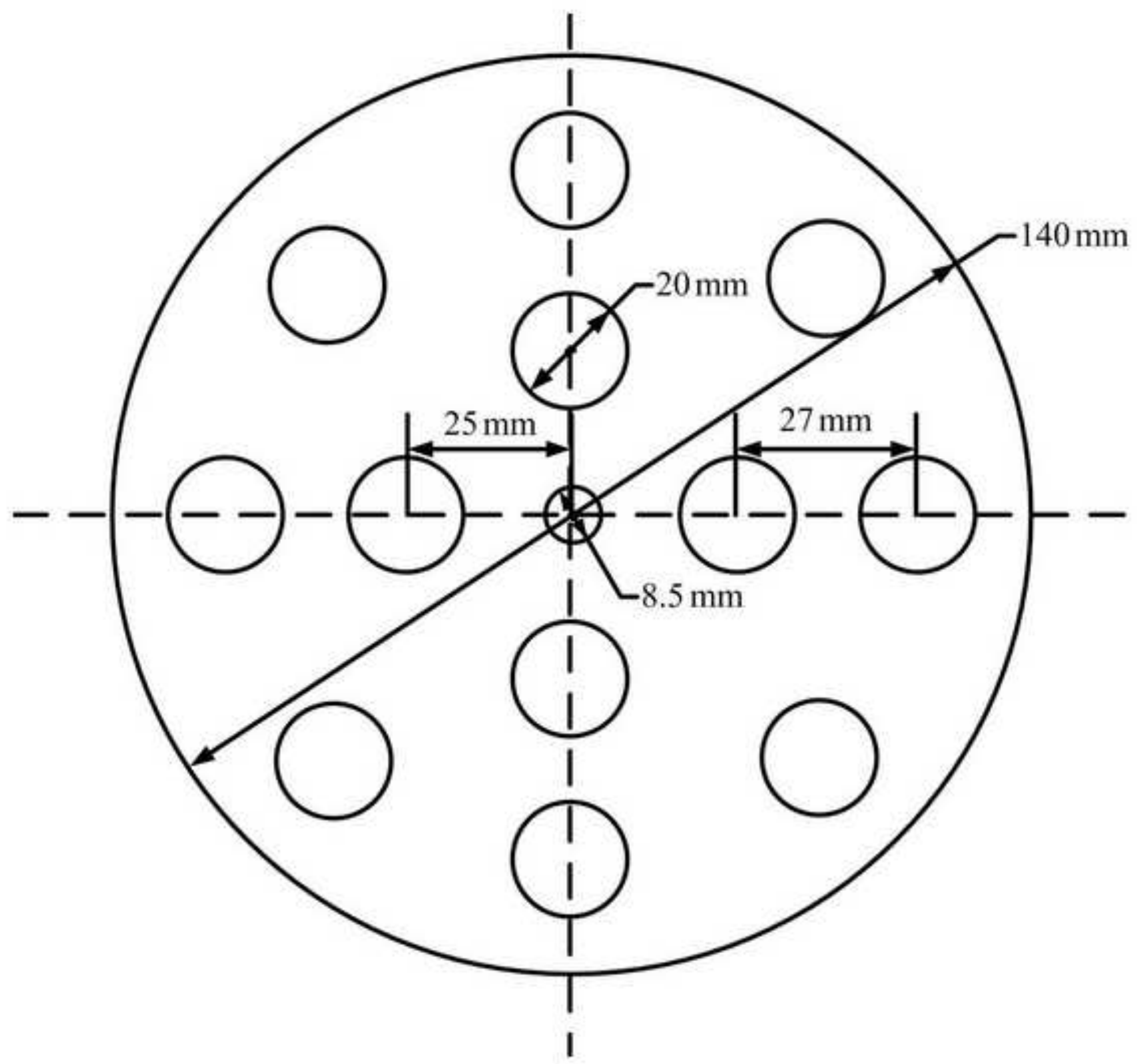



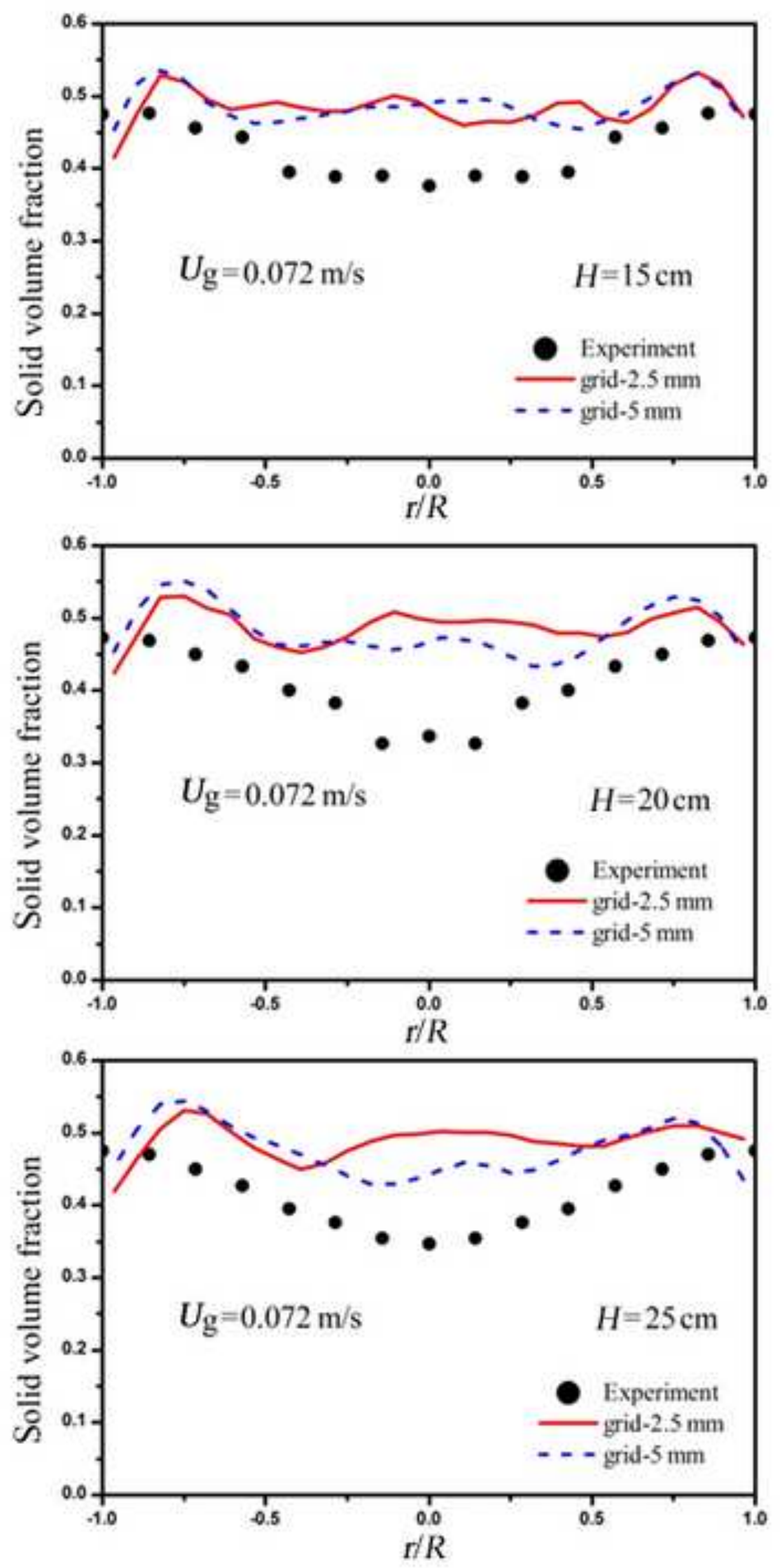

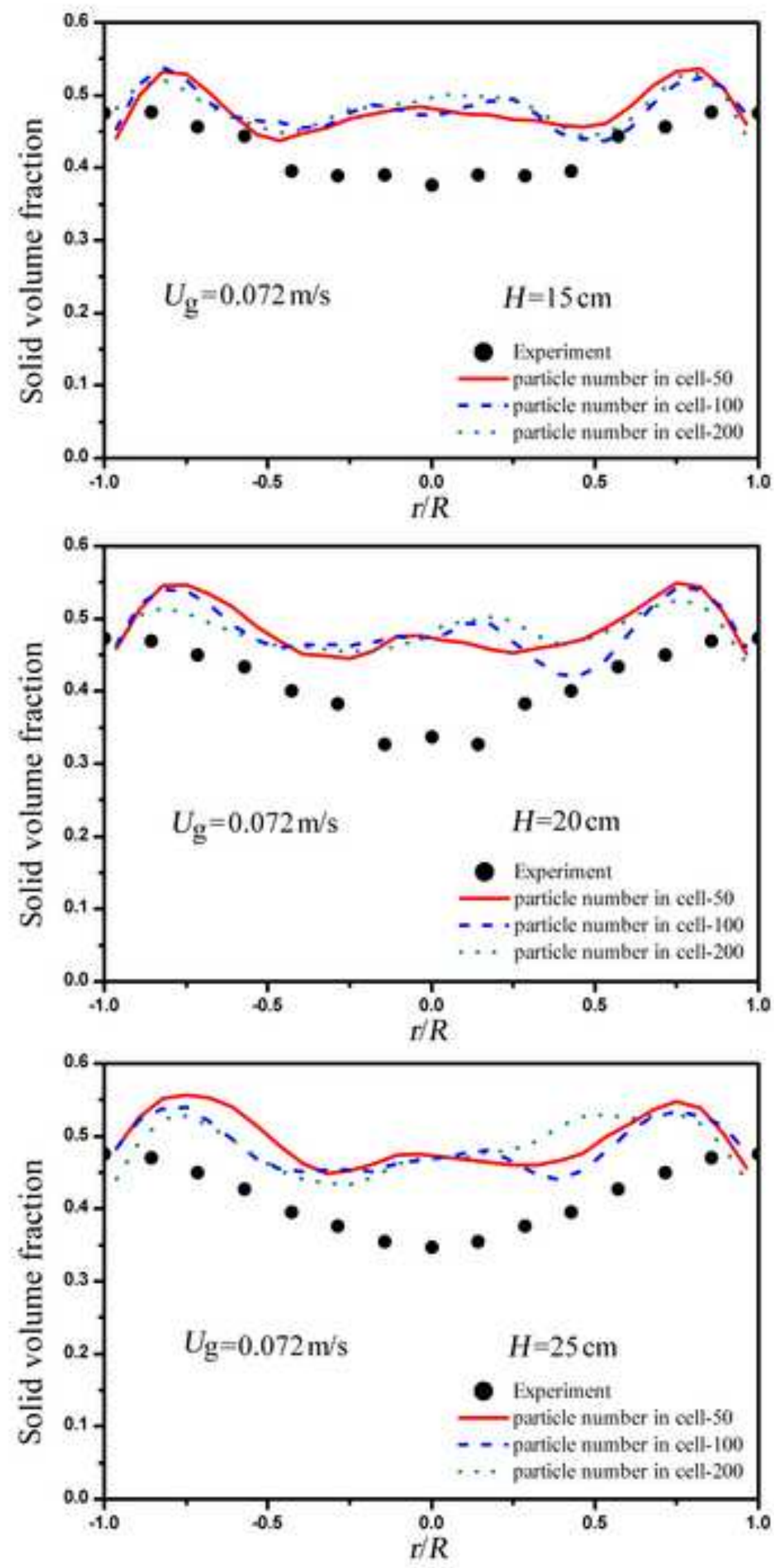
Particles Vol. Frac.

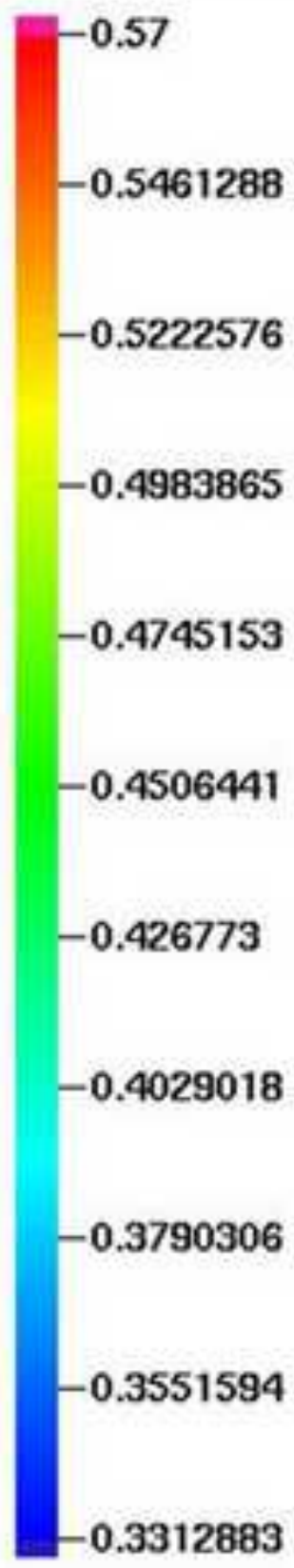

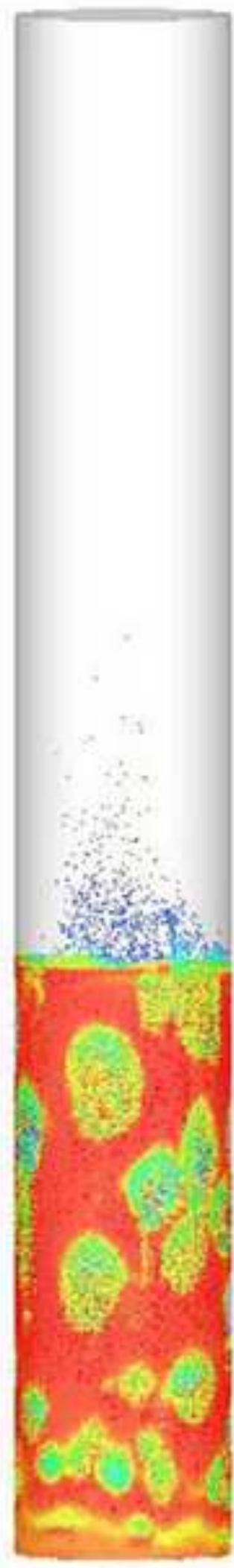

(a)

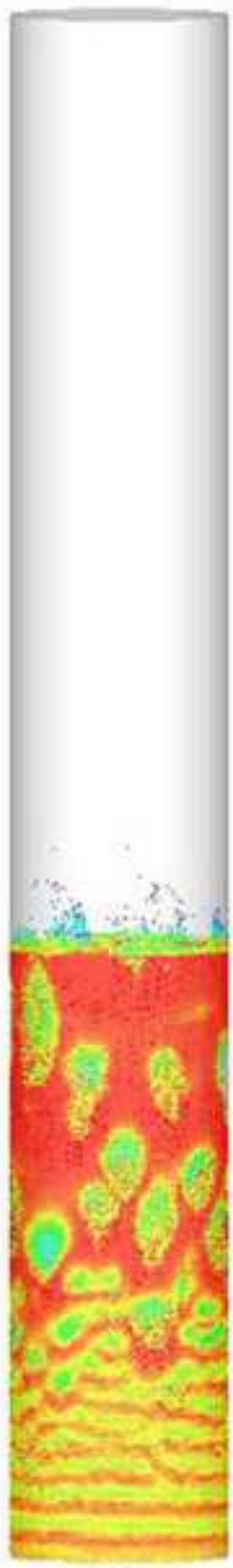

(b)

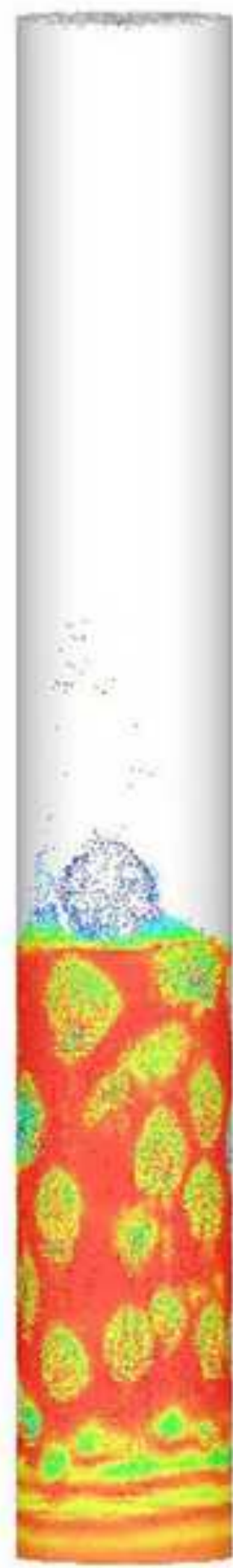

(c) 
figure 07.tif

Click here to download high resolution image
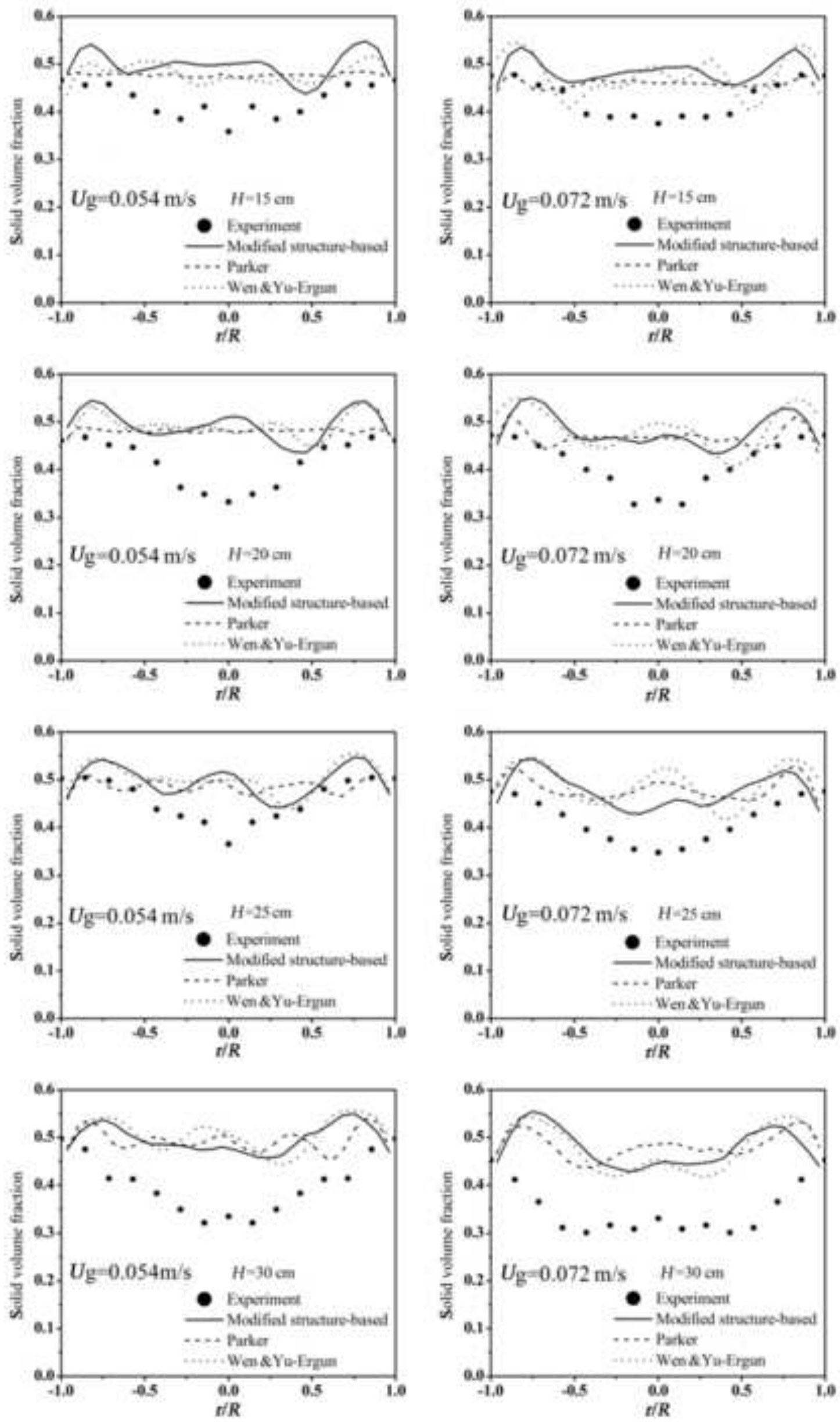

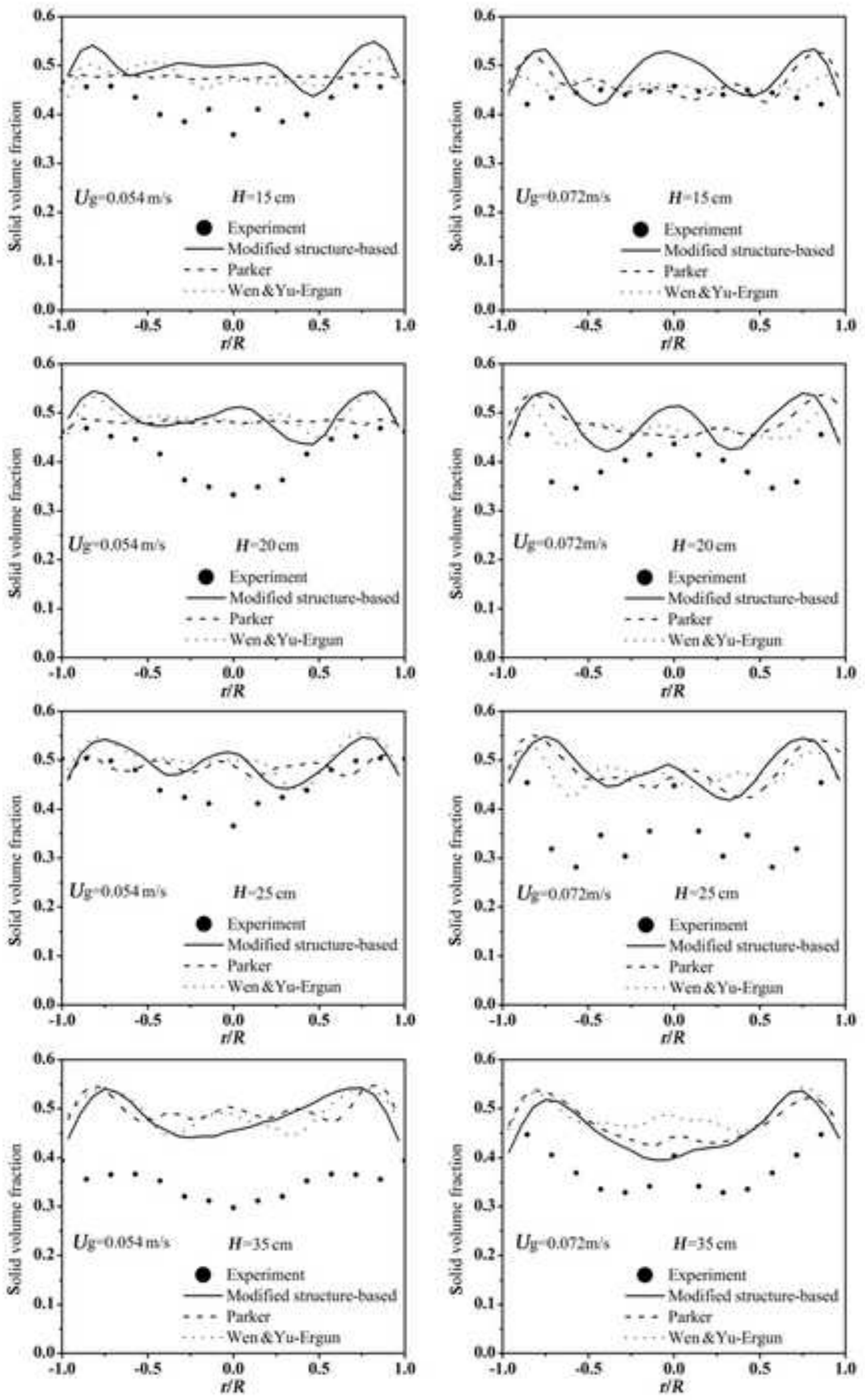
figure 09.tif
Click here to download high resolution image

Particles Vol. Frac.
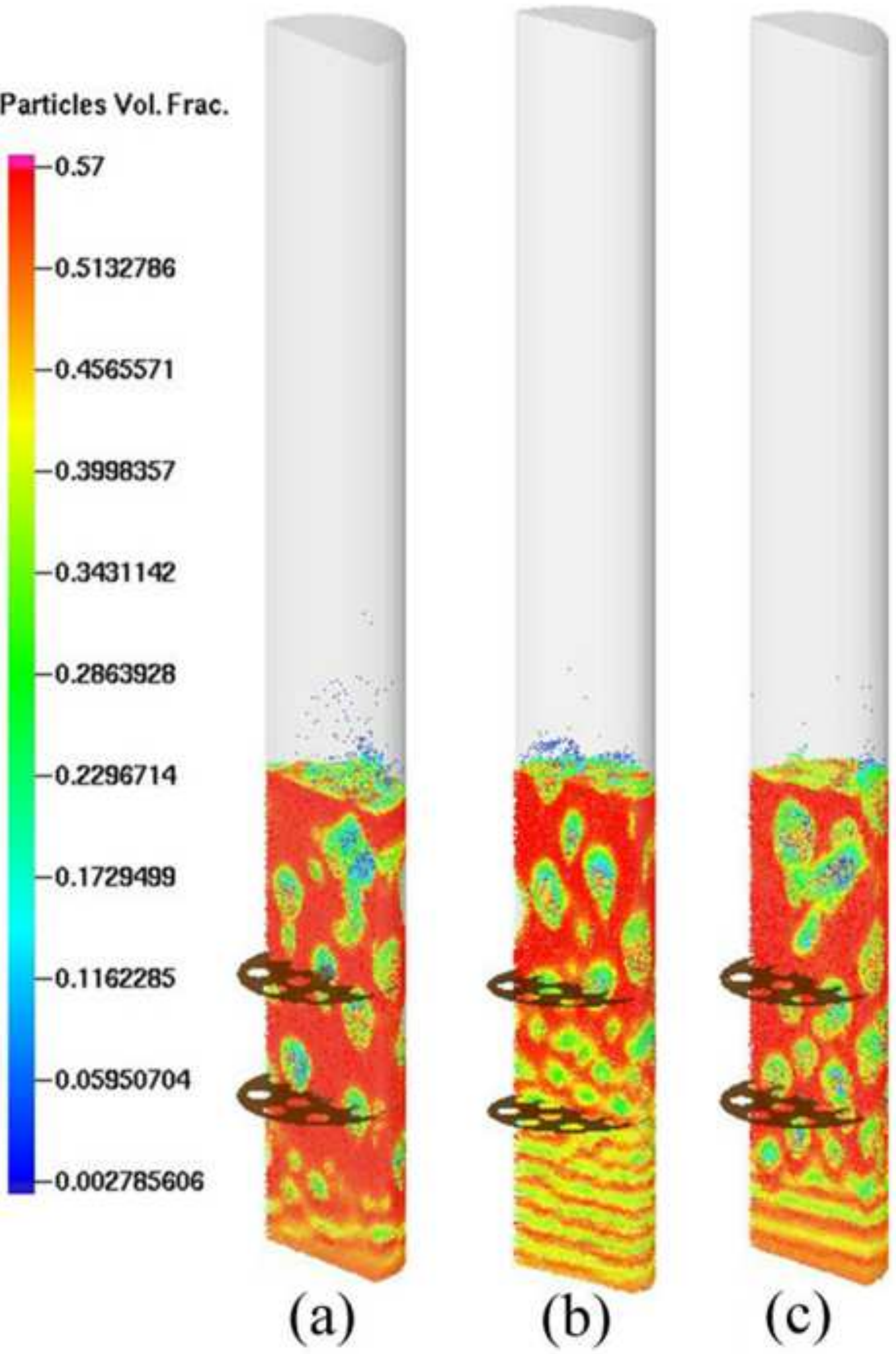

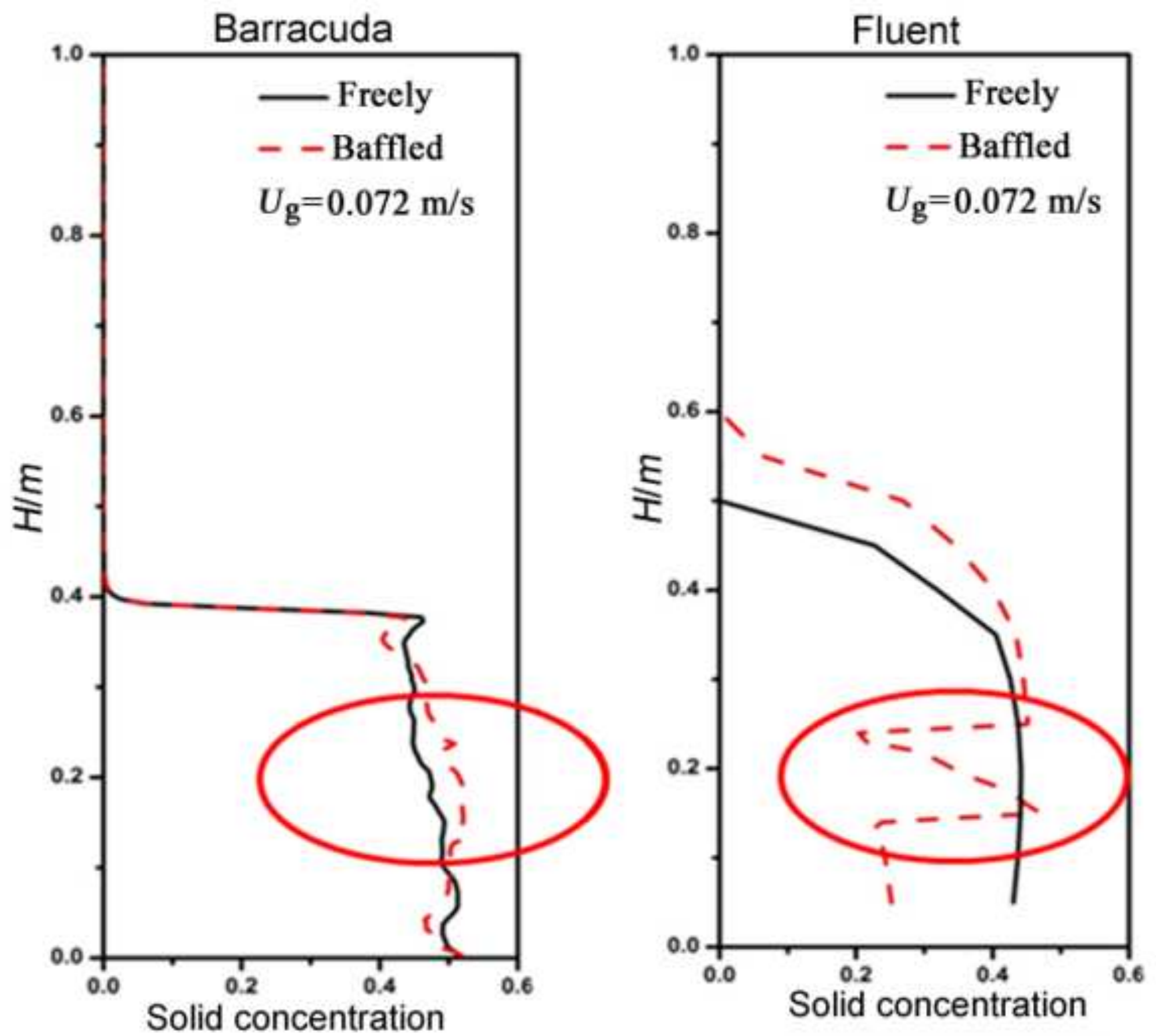


\section{An exploratory study of three-dimensional MP-PIC-based simulation of bubbling fluidized beds with and without baffles}

Shuai Yang ${ }^{\mathrm{a}, \mathrm{b}, \mathrm{c}, \mathrm{d}}$, Hao $\mathrm{Wu}^{\mathrm{c}, *}$, Weigang Lin ${ }^{\mathrm{a}, \mathrm{c}}$, Hongzhong Li ${ }^{\mathrm{a}, *}$, Qingshan $\mathrm{Zhu}^{\mathrm{a}}$

\section{Figure captions:}

Fig. 1. Schematic of experimental set up.

Fig. 2. Size distribution of glass beads.

Fig. 3. Configuration of perforated plate.

Fig. 4. Effect of grid size on simulation results (experimental data from Yang et al., 2015).

Fig. 5. Effect of number of particles per parcel on simulation results (experimental data from Yang et al., 2015).

Fig. 6. Profiles of particle volume fraction at $35 \mathrm{~s}$ calculated with (a) the modified structure-based (MSB) drag model, (b) the Parker drag model, and (c) the Wen-Yu-Ergun (WYE) drag model under a superficial gas velocity of $0.072 \mathrm{~m} / \mathrm{s}$ in the baffle-free bubbling fluidized bed (BFB).

Fig. 7. Comparison of simulated radial distributions of solid volume fraction obtained with the MSB drag model, the Parker drag model, and the WYE drag model under superficial gas velocities of 0.054 and $0.072 \mathrm{~m} / \mathrm{s}$ in the baffle-free BFB (experimental data from Yang et al., 2015).

Fig. 8. Comparison of simulated radial distributions of solid volume fraction obtained with the MSB drag model, the Parker drag model, and the WYE drag model under superficial gas velocities of 0.054 and $0.072 \mathrm{~m} / \mathrm{s}$ in the baffled BFB (experimental data from Yang et al., 2015). 
Fig. 9. Profiles of particle volume fraction at $35 \mathrm{~s}$ calculated with (a) the MSB drag model, (b) the Parker drag model, (c) the WYE drag model under a superficial gas velocity of $0.072 \mathrm{~m} / \mathrm{s}$ in the BFB with two layers of perforated plates.

Fig. 10. Axial distributions of solid volume fraction simulated by Barracuda and Fluent in the baffle-free BFB and the BFB with two layers of perforated plates. 


\section{An exploratory study of three-dimensional MP-PIC-based simulation of bubbling fluidized beds with and without baffles}

Shuai Yang ${ }^{\mathrm{a}, \mathrm{b}, \mathrm{c}, \mathrm{d}}$, Hao $\mathrm{Wu}^{\mathrm{c}, *}$, Weigang Lin ${ }^{\mathrm{a}, \mathrm{c}}$, Hongzhong Li ${ }^{\mathrm{a}, *}$, Qingshan Zhu ${ }^{\mathrm{a}}$

\section{Tables:}

Table 1. Summary of governing equations for Barracuda simulations

Fluid-phase mass equation

Fluid-phase momentum equation

Individual gas species transport equations

Fluid-phase enthalpy equation

Fluid-phase stress

Subgrid turbulence

Fluid heat flux

Enthalpy diffusion

Acceleration on a particle

Equation of solid movement

Lumped-heat equation for a particle

$$
\frac{\partial\left(\theta_{\mathrm{f}} \rho_{\mathrm{f}}\right)}{\partial t}+\nabla \cdot\left(\theta_{\mathrm{f}} \rho_{\mathrm{f}} \mathbf{u}_{\mathrm{f}}\right)=\delta \dot{m}_{\mathrm{p}}
$$

$\frac{\partial\left(\theta_{\mathrm{f}} \rho_{\mathrm{f}} \mathbf{u}_{\mathrm{f}}\right)}{\partial t}+\nabla \cdot\left(\theta_{\mathrm{f}} \rho_{\mathrm{f}} \mathbf{u}_{\mathrm{f}} \mathbf{u}_{\mathrm{f}}\right)=-\nabla p+\mathbf{F}+\theta_{\mathrm{f}} \rho_{\mathrm{f}} \mathbf{g}+\nabla \cdot\left(\theta_{\mathrm{f}} \tau_{\mathrm{f}}\right)$

$\frac{\partial\left(\theta_{\mathrm{f}} \rho_{\mathrm{f}} Y_{\mathrm{f}, i}\right)}{\partial t}+\nabla \cdot\left(\theta_{\mathrm{f}} \rho_{\mathrm{f}} Y_{\mathrm{f}, i} \mathbf{u}_{\mathrm{f}}\right)=\nabla \cdot\left(\rho_{\mathrm{f}} D \theta_{\mathrm{f}} \nabla Y_{\mathrm{f}, i}\right)+\delta \dot{m}_{i, \text { chem }}$

$\frac{\partial}{\partial t}\left(\theta_{\mathrm{f}} \rho_{\mathrm{f}} h_{\mathrm{f}}\right)+\nabla \cdot\left(\theta_{\mathrm{f}} \rho_{\mathrm{f}} h_{\mathrm{f}} \mathbf{u}_{\mathrm{f}}\right)=\theta_{\mathrm{f}}\left(\frac{\partial p}{\partial t}+\mathbf{u}_{\mathrm{f}} \cdot \nabla p\right)+\phi-\nabla \cdot\left(\theta_{\mathrm{f}} \mathbf{q}\right)+\dot{Q}+S_{\mathrm{h}}+\dot{q}_{\mathrm{D}}$

$\tau_{\mathrm{f}, i j}=\mu\left(\frac{\partial u_{i}}{\partial x_{j}}+\frac{\partial u_{j}}{\partial x_{i}}\right)-\frac{2}{3} \mu \delta_{i j} \frac{\partial u_{i}}{\partial u_{j}}$

$$
\mu_{\mathrm{t}}=C \rho_{\mathrm{f}} \Delta^{2} \sqrt{\left(\frac{\partial u_{i}}{\partial x_{j}}+\frac{\partial u_{j}}{\partial x_{i}}\right)^{2}}
$$

$\mathbf{q}=-\lambda_{\mathrm{f}} \nabla T_{\mathrm{f}}$

$\dot{\mathbf{q}}_{\mathrm{D}}=\sum_{i=1}^{N_{\mathrm{s}}} \nabla \cdot\left(h_{i} \theta_{\mathrm{f}} \rho_{\mathrm{f}} D \nabla Y_{\mathrm{f}, i}\right)$

$\frac{d \mathbf{u}_{\mathrm{p}}}{d t}=D_{\mathrm{p}}\left(\mathbf{u}_{\mathrm{f}}-\mathbf{u}_{\mathrm{p}}\right)-\frac{1}{\rho_{\mathrm{f}}} \nabla p-\frac{1}{\theta_{\mathrm{p}} \rho_{\mathrm{p}}} \nabla \tau_{\mathrm{p}}+g+\frac{\overline{\mathbf{u}}_{\mathrm{p}}-\mathbf{u}_{\mathrm{p}}}{\tau_{\mathrm{D}}}$

$$
\mathbf{u}_{\mathrm{p}}=\frac{d x_{\mathrm{p}}}{d t}
$$

$C_{\mathrm{V}} \frac{d T_{\mathrm{p}}}{d t}=\frac{1}{m_{\mathrm{p}}} \frac{\lambda_{\mathrm{f}} N u_{\mathrm{f}, \mathrm{p}}}{2 r_{\mathrm{p}}} A_{\mathrm{p}}\left(T_{\mathrm{f}}-T_{\mathrm{p}}\right)$ 
Table 2. Physical properties of the particles

\begin{tabular}{ll}
\hline Mean diameter, $d_{\mathrm{p}}(\mu \mathrm{m})$ & 53 \\
Particle density, $\rho_{\mathrm{p}}\left(\mathrm{kg} / \mathrm{m}^{3}\right)$ & 2450 \\
Bulk density, $\rho_{\mathrm{b}}\left(\mathrm{kg} / \mathrm{m}^{3}\right)$ & 1395 \\
Minimum fluidization velocity, $\mu_{\mathrm{mf}}(\mathrm{m} / \mathrm{s})$ & 0.0051 \\
\hline
\end{tabular}

Table 3. Summary of parameters used in Barracuda 17.0

\begin{tabular}{ll}
\hline Initial bed height $(\mathrm{m})$ & 0.335 \\
Initial solids concentration & 0.56 \\
Particle sphericity & 0.8 \\
Superficial gas velocity $(\mathrm{m} / \mathrm{s})$ & $0.054,0.072$ \\
Initial fluid pressure $(\mathrm{kPa})$ & 106 \\
Flow time (s) & 35 \\
Average time of results (s) & 15 \\
\hline
\end{tabular}

Table 4 . Heterogeneous index under superficial gas velocities of 0.054 and $0.072 \mathrm{~m} / \mathrm{s}$

\begin{tabular}{ccc}
\hline Gas velocity $(\mathrm{m} / \mathrm{s})$ & Heterogeneous index, $H_{\mathrm{d}}$ & Application range $\left(\theta_{f}\right)$ \\
\hline 0.054 & $H_{\mathrm{d}}=7.92705-34.65591 \theta_{\mathrm{f}}+46.64973 \theta_{\mathrm{f}}^{2}-17.02621 \theta_{\mathrm{f}}^{3}$ & $\theta_{\mathrm{mf}}<\theta_{\mathrm{f}} \leq 0.79701$ \\
0.072 & $H_{\mathrm{d}}=7.94392-34.52282 \theta_{\mathrm{f}}+46.93384 \theta_{\mathrm{f}}^{2}-18.24157 \theta_{\mathrm{f}}^{3}$ & $\theta_{\mathrm{mf}}<\theta_{\mathrm{f}} \leq 0.77901$ \\
\hline
\end{tabular}

